\title{
A versatile route to polythiophenes with functional pendant groups using alkyne chemistry
}

\author{
Xiao Huang ${ }^{*}$, Li Yang ${ }^{2}$, Rikard Emanuelsson ${ }^{2}$, Jonas Bergquist ${ }^{1}$, Maria Strømme ${ }^{2}$, \\ Martin Sjödin² and Adolf Gogoll ${ }^{* 1}$
}

\author{
Full Research Paper \\ Address: \\ ${ }^{1}$ Department of Chemistry - BMC, Uppsala University, Box 576, 751 \\ 23 Uppsala, Sweden and ${ }^{2}$ Nanotechnology and Functional Materials, \\ Department of Engineering Sciences, Uppsala University, Box 534, \\ 75121 Uppsala, Sweden \\ Email: \\ Xiao Huang* - xiao.huang@kemi.uu.se; Adolf Gogoll* - \\ Adolf.gogoll@kemi.uu.se \\ * Corresponding author \\ Keywords: \\ electropolymerization; functional polymers; polythiophene; \\ Sonogashira coupling; thiophene
}

\author{
Beilstein J. Org. Chem. 2016, 12, 2682-2688. \\ doi:10.3762/bjoc. 12.265 \\ Received: 19 September 2016 \\ Accepted: 22 November 2016 \\ Published: 09 December 2016 \\ Associate Editor: P. J. Skabara \\ (c) 2016 Huang et al.; licensee Beilstein-Institut. \\ License and terms: see end of document.
}

\begin{abstract}
A new versatile polythiophene building block, 3-(3,4-ethylenedioxythiophene)prop-1-yne (pyEDOT) (3), is prepared from glycidol in four steps in $28 \%$ overall yield. pyEDOT features an ethynyl group on its ethylenedioxy bridge, allowing further functionalization by alkyne chemistry. Its usefulness is demonstrated by a series of functionalized polythiophene derivatives that were obtained by pre- and post-electropolymerization transformations, provided by the synthetic ease of the Sonogashira coupling and click chemistry.
\end{abstract}

\section{Introduction}

Currently organic conjugated polymers are attracting considerable interest for various applications in plastic electronics. In particular, poly(3,4-ethylenedioxythiophene) (PEDOT) [1] and its derivatives [2-7] play an increasingly important role in this field. The attractiveness of PEDOT in organic electronics is due to its electrochemical stability in combination with conductivity and solution processability. Recently demonstrated successful applications include electrochromic materials [8], energy storage materials [2-9], as well as ion sensing devices [10], biosensors [11], and thermoelectric polymers [12]. There- fore, the chemistry of its building block 3,4-ethylenedioxythiophene (EDOT) and the functionalization of the basic structure have been attracting interest as well [13]. The vast amount of research on functionalized polypyrroles [14] and polythiophenes [15] demonstrates that the attachment of functionalized pendant groups to the conjugated polymer backbone provides access to novel properties and applications. An EDOT building block to which highly functionalized pendants can easily be attached thus offers the possibility for rapid access to new functionalized materials. 


\section{Results and Discussion}

EDOT functionalization protocols typically involve manipulations of the ethylenedioxy bridge. Thus, the hydroxylmethyl derivative EDOT- $\mathrm{CH}_{2} \mathrm{OH}$ [16], aminomethyl derivative EDOT$\mathrm{CH}_{2} \mathrm{NH}_{2}$ [17] and the methylenethiol derivative EDOT- $\mathrm{CH}_{2} \mathrm{SH}$ [18], as nucleophiles, as well as the halomethyl derivative EDOT- $\mathrm{CH}_{2}-\mathrm{Cl} / \mathrm{Br}[6,9]$ and the exomethylene-EDOT [19] as electrophiles, can be used to form ether, thioether, ester, amine and peptide linkages with the pendant groups. The polar reaction conditions required for their synthesis exclude the use of pendant groups featuring electrophilic or nucleophilic functional moieties, such as esters and alkyl halide, or alcohols and phenols. Furthermore, in the case of EDOT- $\mathrm{CH}_{2}-\mathrm{Cl} / \mathrm{Br}$, the $\alpha$-hydrogen on the ethylene bridge is acidic and it thus favors $\beta$-elimination under basic conditions leading to exomethyleneEDOT [19]. Therefore, the usage of basic nucleophiles is problematic. Moreover, these heteroatom-based linkers between the polymer backbone and the pendant group usually have limited tolerance to acidic or basic conditions promoting hydrolysis, and some of them are electrochemically redox active. The stability of the linker would thus constitute an additional parameter to consider when designing functional polymers.

The alkyne group is a versatile synthetic building block which can be functionalized in a number of fashions [20-23]. These include, e.g., well-developed cross-coupling reactions, cycloaddition reactions, radical reactions and reductive addition reactions. A terminal alkyne can also react as nucleophile or serve as synthon for pyrrole rings $[24,25]$. Thus we here fuse the rich alkyne chemistry to the EDOT backbone, resulting in a novel EDOT derivative, the 3-(EDOT)prop-1-yne (pyEDOT, 3). pyEDOT provides a useful synthon for the synthesis of a variety of EDOT-based polymerizable building blocks. This new EDOT functionalization strategy (Scheme 1), including the polymerization of the resulting building blocks, we illustrate by introducing two examples of such functionalization using a Sonogashira cross-coupling [26] and an azide-alkyne Huisgen cycloaddition [27]. One of the advantages of the cross-coupling and click chemistry is that it allows for reaction conditions tolerant for nearly all of the above mentioned functional groups. Additionally, these functionalizations require only readily available starting materials. A related concept, i.e., attachment of a terminal alkyne moiety to the polymerizable thiophene derivative ProDOT, an EDOT analogue, and its utilization for "click" chemistry has been reported [28]. However, this involved an ether linkage. Furthermore, substantial differences between ProDOT and EDOT polymers regarding their electrochemical properties have been described [29].

Scheme 2 shows the synthesis of pyEDOT 3. It starts with glycidol that can be economically prepared by the epoxidation of allyl alcohol [30]. The alkynediol 2 was prepared from glycidol by using a four-step sequence reported by Pattenden and co-workers [31]. The presence of catalytic $p$-toluenesulfonic acid ( $p$-TSA) in the toluene solution of 3,4dimethoxythiophene and 2 resulted in a transetherification reaction to form pyEDOT, which was isolated as light yellow oil by chromatography with a yield of $64 \%$. The yield of the transetherification product was influenced by two factors. Substrate concentrations below $0.5 \mathrm{M}$ resulted in much less polymerization, leaving more diols for transetherification. However, still lower concentrations of less than $0.1 \mathrm{M}$ resulted in lower yields, probably due to decrease of the reaction rate. The yield could also be improved by dividing the addition of the diol 2 into several portions, added over two days. Two or three portions were found to result in the highest yield, with more portions not changing the yield significantly.

Prior to the high yielding pyEDOT synthesis presented here, we attempted to synthesize ethynyl-(EDOT) 8 (eEDOT) and ethynyltrimethylsilane-(EDOT) 8' (etEDOT) with the alkyne moiety directly attached to the ethylenedioxyl bridge, albeit with much lower yield (Scheme 3). The synthesis started from economically available D-mannitol diketal, 1,2:5,6-bis-O-(1methylethylidene)-D-mannitol which can be obtained via the hydrogenation of common table sugar [32]. Oxidation of this

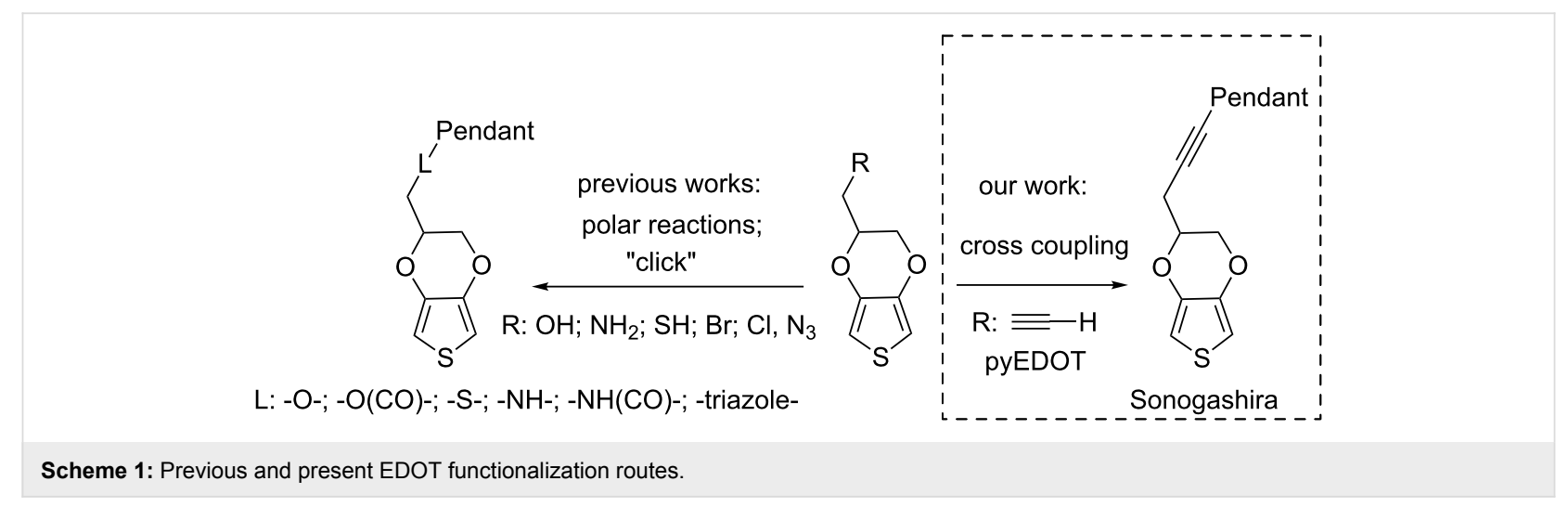




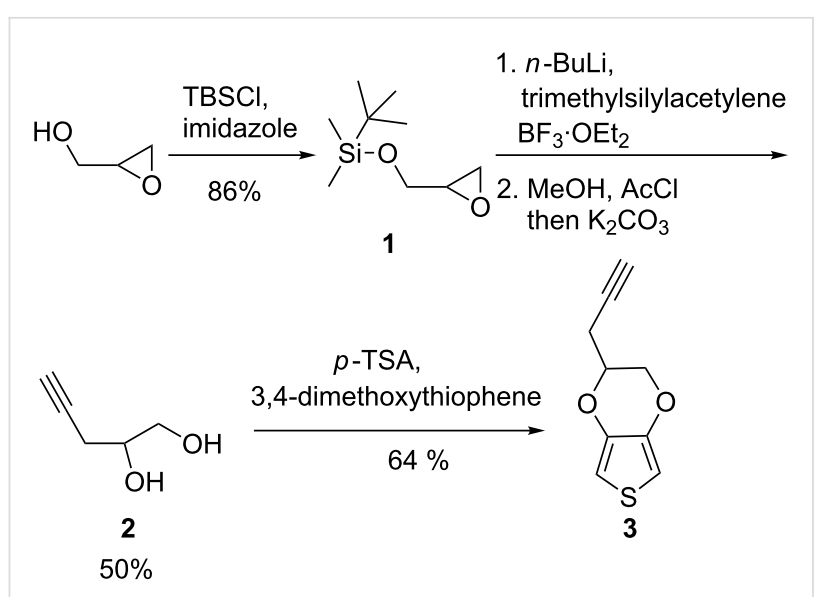

Scheme 2: The synthetic route from glycidol to pyEDOT (3).

diketal by $\mathrm{NaIO}_{4}$ led to glyceraldehyde [33], which was transformed into the dibromoolefin 5 by Corey-Fuchs reaction. Dibromoolefin 5 was dehalogenated by adding 2 equivalents of $n$-butyllithium to produce 4-ethynyl-2,2-dimethyl-1,3-dioxolane 6, which was deprotected in acid to give ethynyldiol 7 . However, the transetherification of 3,4-dimethoxythiophene to produce $\mathbf{8}$ turned out to be difficult, with very low yield of only $6 \%$. Thus, diol 7 was modified by protecting the ethynyl function with a TMS group, yielding 7', expecting an improved yield from a better solubility of this diol in toluene. However, the transetherification reaction gave almost no conversion after 2 days. By changing the solvent to dichloroethane a yield of $12 \%$ could be obtained, but this would not be sufficient for large scale production, besides considering the environmental impact of requiring a halogenated solvent. Comparing the structural difference between diols 2 and 7, these results emphasized that the isolation of the alkyne from the ethylenediol by an $\mathrm{sp}^{3}$ carbon increased the yield of the transetherification reaction significantly. Attempts were also made to attach an alkyne to EDOT via the reaction between hydroxymethyl EDOT and propargyl tosylate using DABCO as catalyst, but it led to a very low yield and this EDOT-propargyl product was very sensitive to acidic conditions. Considering the robust production of functional alkyne-EDOT and its chemical stability, pyEDOT 3 was thus selected as the precursor of choice for future synthetic and electrochemical studies. pyEDOT can be stored at room temperature over months in an acid-free environment.

The synthetic utility of pyEDOT is demonstrated by the following examples involving a range of pendant groups. The electron acceptor units diethyl terephthalate (DET) and 9,10anthraquinone (AQ) are of particular interest for their redox chemistry in energy storage applications [34]. Their ester and quinone moieties are vulnerable in nucleophilic and acidic environments. Furthermore, the viologen moiety, available from 4,4'-bipyridine (BP) has potential for energy storage and electrochromic applications $[35,36]$, but it has previously been anchored to a polymer backbone only by oxidative coupling via the nitrogen atom. As shown by our synthesis, all of these electron acceptor units were tolerant to Sonogashira coupling conditions, which produced new EDOT derivatives 9, 10, 11 and 12 (Scheme 4). The Sonogashira couplings were performed be-

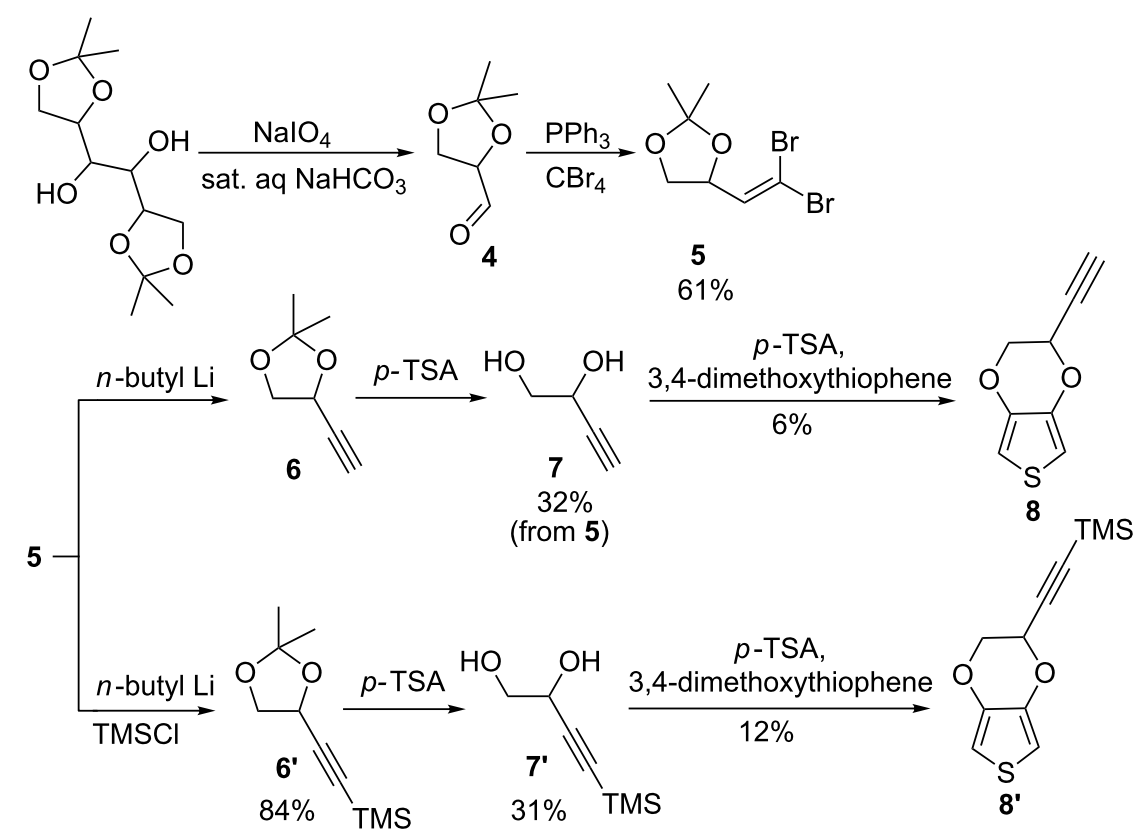

Scheme 3: The synthetic route from D-mannitol diketal to eEDOT 8 and TMS-eEDOT 8'. 
tween the alkyne terminal of pyEDOT and a brominated ring carbon of the pendant group precursors, with yields of $61 \%(9)$, $82 \%$ (10) and 65\% (12), respectively. Methylation of bipyridyl intermediate 10 by methyl iodide produced viologen derivative 11 after exchanging the iodide for the $\mathrm{PF}_{6}{ }^{-}$anion. For the methylation step drying of both the reactants $\mathbf{1 0}$ and methyl iodide and the solvent was essential, since its omission resulted in polymerization of the viologen-pyEDOT, as indicated by ${ }^{1} \mathrm{H}$ NMR (see Supporting Information File 1, Figure S11). We suspect that the polymerization was triggered by the acid generated from methyl iodide reacting with water. Interestingly, the colors of viologen can be tuned by introducing various substituents at the nitrogen sites [37]. The synthesis of 11 illustrates the ease of functionalizing viologen on both nitrogens and it can potentially be used for studying synergic electrochromism coupled with PEDOT [35]. Diethyl 2-bromoterephthalate and 2-bromo4,4'-bipyridine were prepared according to reported procedures $[38,39]$. The electron acceptor phthalimide (PT) was attached to EDOT via cycloaddition between the alkyne and an alkylazide to produce derivative $\mathbf{1 3}$ (Scheme 4). Regioselective formation of 13 involved the $\mathrm{Cu}(\mathrm{I})$-catalyzed Huisgen 1,3-dipolar cycloaddition between $N$-(2-azidoethyl)phthalimide and the alkyne terminal of pyEDOT under ultrasound conditions in $73 \%$ yield. Detailed synthetic routes are presented in Supporting Information File 1.

Figure 1a shows the cyclic voltammograms (CVs) for electrochemical polymerization of pyEDOT on a glassy carbon working electrode. For comparison, the $\mathrm{CV}$ for electrochemical polymerization of pristine EDOT under the same conditions is shown in Figure 1b. Similar voltammetric responses were obtained for the polymerization of pyEDOT and EDOT, with increased current in the potential region from -1.2 to $0.6 \mathrm{~V}$ vs ferrocene/ferrocenium $\left(\mathrm{Fc}^{+} / \mathrm{Fc}^{0}\right)$ during polymerization cycling. Apparently, the presence of an ethynyl group on pyEDOT did not disturb the polymerization of the EDOT backbone. The CVs of pyEDOT indicated an irreversible reduction reaction at a potential lower than $-2.4 \mathrm{~V} \mathrm{vs} \mathrm{Fc}^{+} / \mathrm{Fc}^{0}$ as shown in the inset of Figure 1a. This is believed to indicate the reduction of the triple bond. The ease of pyEDOT polymerization should also allow for further post-polymerization functionalization [40].

Figure 2 presents the CVs of the pyEDOT derivative monomers and their polymerization in $\mathrm{MeCN}$ solution. All compounds showed the electrochemical activities of both the pendant group and the EDOT moiety individually, giving redox reactions of the pendant groups in a negative potential region (the red curves in the insets of Figure 2) and oxidation of the EDOT unit in a more positive potential region (the black curves in the insets of Figure 2). Comparable voltammetric behaviors for the polymerization of pyEDOT-DeT (9) and pyEDOT-AQ

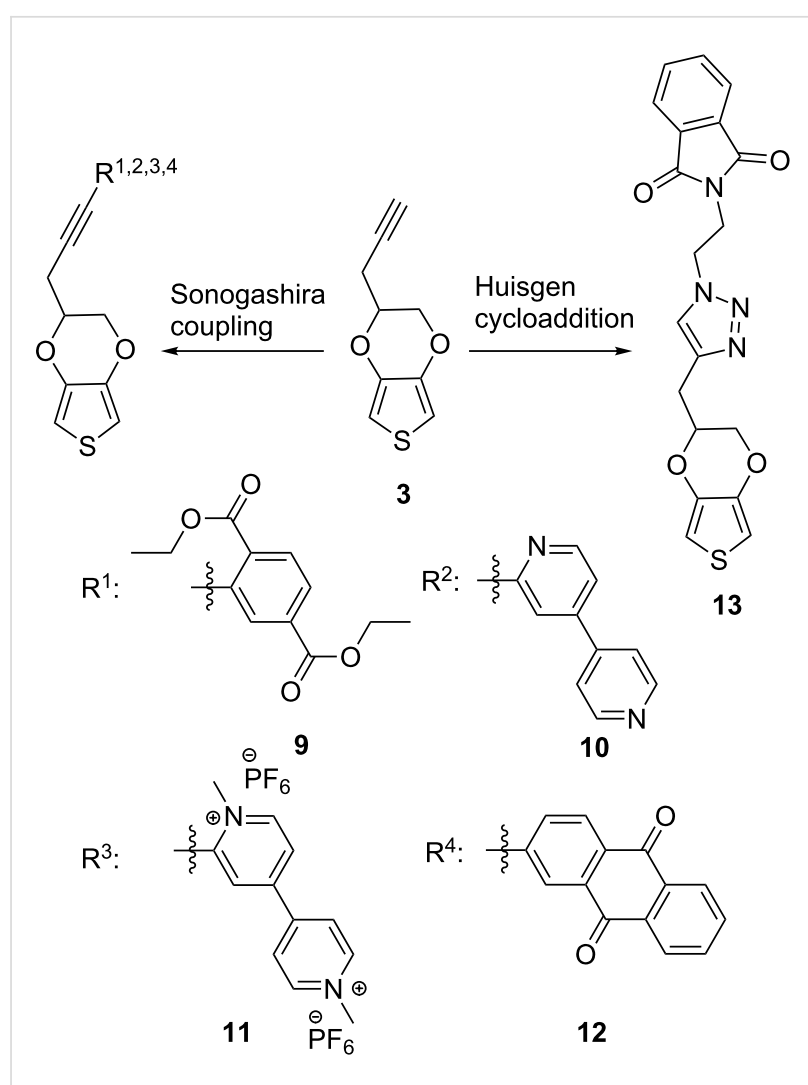

Scheme 4: New EDOT derivatives 9-13 accessible from pyEDOT with bromo-pendant group precursors via Sonogashira cross coupling and with an azide pendant group precursor via Huisgen cycloaddition.

(12) were obtained, similar to those of pyEDOT and EDOT as presented in Figure 1. For pyEDOT-MVPF 6 (11), the polymerization was performed in a potential region covering both EDOT-based oxidation and MV-centered reductions. The buildup of the MV-centered redox peaks is clearly evident at $-0.8 \mathrm{~V}$ vs $\mathrm{Fc}^{+} / \mathrm{Fc}^{0}$ and $-1.2 \mathrm{~V}$ vs $\mathrm{Fc}^{+} / \mathrm{Fc}^{0}$ corresponding to the $\mathrm{MV}^{2+/+}$ redox reaction and the $\mathrm{MV}^{+/ 0}$ redox reaction, respectively. The $\mathrm{CVs}$ of these polymers can be found in Supporting Information File 1, Figure S39, and the polymer properties will be characterized further in a separate study. The successful polymerization of these functionalized pyEDOT monomers exemplifies the capabilities that pyEDOT derivatives can bring for the synthesis of new polymers and property studies.

The phthalimide-EDOT derivative $\mathbf{1 3}$ failed to polymerize. A plausible reason could be an interference of the electron rich aromatic moieties with the thiophene radical cations formed during polymerization, in analogy to previous suggestions from Bäuerle et al. for triazolomethyl-substituted EDOT. Post-functionalization of the azido-PEDOT polymer by click chemistry turned out to be a solution to this problem [41]. To confirm the viability of this alternative, in a similar fashion, post-functionalization of the poly(pyEDOT) was performed in an acetonitrile 


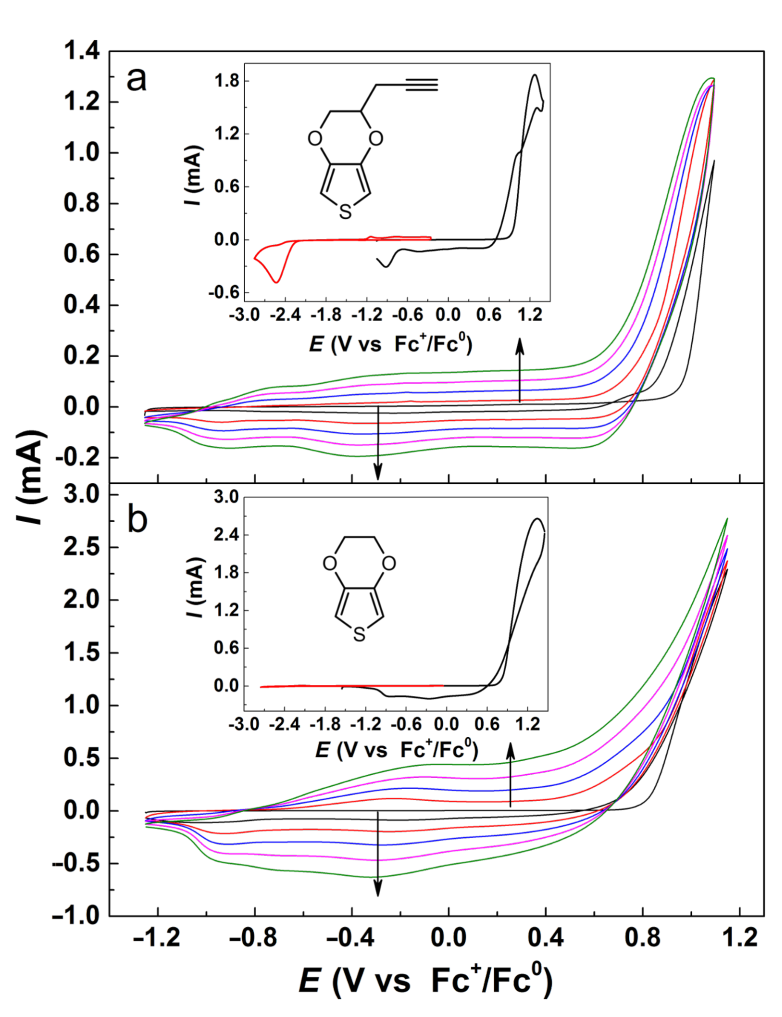

Figure 1: CVs of electrochemical polymerization of (a) pyEDOT 3 and (b) EDOT in MeCN solution with $0.1 \mathrm{M} \mathrm{TEAPF}_{6}$, glassy carbon electrode, $0.1 \mathrm{~V} \mathrm{~s}^{-1}$. Insets show the structure and voltammograms for the monomers.

solution of phthalimide-azide in the presence of catalytic amounts of $\mathrm{Cu}^{+}\left(\mathrm{CH}_{3} \mathrm{CN}\right)_{4} \mathrm{PF}_{6}{ }^{-}$and elemental copper. The reaction to correspondingly functionalized PEDOT was stopped after three days at room temperature. After washing the "click"-functionalized electrode it was characterized electrochemically. The redox peaks appearing at -2.0 to $-1.5 \mathrm{~V}$ vs $\left(\mathrm{Fc}^{+} / \mathrm{Fc}^{0}\right)$ indicated the attachment of phthalimide to the PEDOT backbone (Supporting Information File 1, Figure S40).

\section{Conclusion}

In conclusion, we have introduced a new functional pyEDOT featuring a terminal alkyne which endows EDOT or PEDOT functionalization with the rich chemistry of alkynes. We exemplify this application of a $\mathrm{C}-\mathrm{C}$ bond forming synthesis for the PEDOT functionalization by a Sonogashira coupling yielding the first terephthalate functionalized EDOT monomer as well as a viologen unit with symmetrical $\mathrm{N}$-substitution attached to an EDOT core. These new monomers have been successfully electropolymerized on a glassy carbon electrode, giving a robust electroactive film. Additionally, we show that alkyne-PEDOT can also be post-functionalized in a "click" fashion. All of these proved the synthetic and electrochemical utilities of pyEDOT. Thus, we believe that the pyEDOT synthon provides valuable

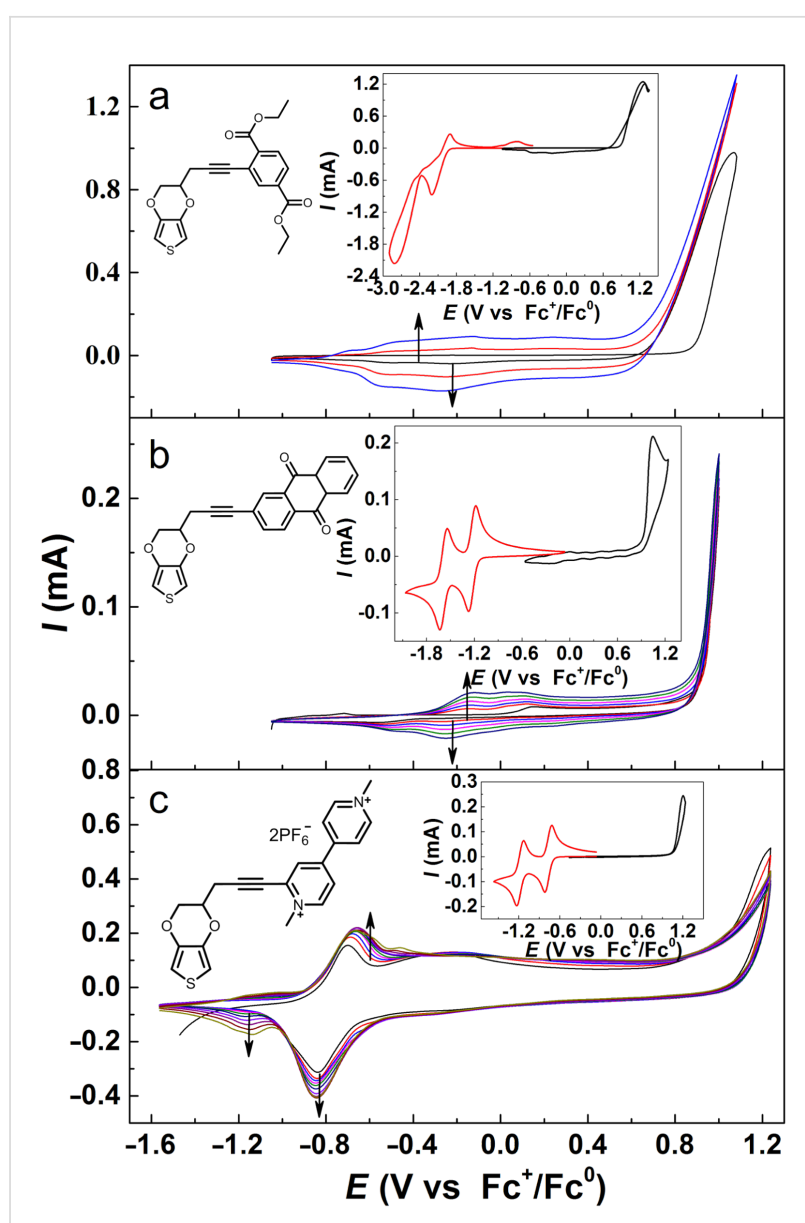

Figure 2: CVs of electrochemical polymerization of (a) pyEDOT-DeT (9), (b) pyEDOT-AQ (12) and (c) pyEDOT-MVPF6 (11) in MeCN with $0.1 \mathrm{M} \mathrm{TEAPF}_{6}, \mathrm{GC}, 0.1 \mathrm{~V} \mathrm{~s}^{-1}$. Insets show the structure and voltammograms for the monomers. Polymerization of pyEDOT-MVPF 6 was performed on a PEDOT-modified GC electrode.

starting points for future new functionalized EDOT monomers and following polymer or oligomer research.

\section{Supporting Information}

\section{Supporting Information File 1}

Experimental details, NMR spectra, IR spectra, and HRMS for all products and electrochemistry data.

[http://www.beilstein-journals.org/bjoc/content/ supplementary/1860-5397-12-265-S1.pdf]

\section{Acknowledgments}

The Swedish Research Council (VR), the Swedish Foundation for Strategic Research (SSF), the Olle Byggmästare Foundation, the Swedish Energy Agency, and the Swedish Centre for Smart Grids and Energy Storage (SweGRIDS) are acknowledged for their financial support. J. B. acknowledges the Swedish 
Research Council for Grant VR 621-2011-4423 for the purchase of the mass spectrometer. J. B. acknowledges Dr Konstantin Artemenko and the Swedish Research Council for grant 20154870 for the support with the FTICR mass spectrometry.

\section{References}

1. Skotheim, T. A.; Reynolds, J. R. Handbook of Conducting Polymers, 3rd ed.; CRC Press: Boca Raton: FL, 2007.

2. Groenendaal, L.; Jonas, F.; Freitag, D.; Pielartzik, H.; Reynolds, J. R. Adv. Mater. 2000, 12, 481-494. doi:10.1002/(SICI)1521-4095(200004)12:7<481::AID-ADMA481>3.0.C O;2-C

3. Groenendaal, L.; Zotti, G.; Aubert, P.-H.; Waybright, S. M.; Reynolds, J. R. Adv. Mater. 2003, 15, 855-879. doi:10.1002/adma.200300376

4. Kirchmeyer, S.; Reuter, K. J. Mater. Chem. 2005, 15, 2077-2088. doi:10.1039/b417803n

5. Segura, J. L.; Gómez, R.; Reinold, E.; Bäuerle, P. Org. Lett. 2005, 7, 2345-2348. doi:10.1021/ol050573m

6. Segura, J. L.; Gómez, R.; Blanco, R.; Reinold, E.; Bäuerle, P. Chem. Mater. 2006, 18, 2834-2847. doi:10.1021/cm0602085

7. Sassi, M.; Salamone, M. M.; Ruffo, R.; Mari, C. M.; Pagani, G. A.; Beverina, L. Adv. Mater. 2012, 24, 2004-2008. doi:10.1002/adma.201200111

8. Sotzing, G. A.; Reynolds, J. R.; Steel, P. J. Adv. Mater. 1997, 9, 795-798. doi:10.1002/adma.19970091005

9. Conte, S.; Rodriguez-Calero, G. G.; Burkhardt, S. E.; Lowe, M. A.; Abruña, H. D. RSC Adv. 2013, 3, 1957-1964. doi:10.1039/C2RA22963C

10. Perepichka, I. F.; Besbes, M.; Levillain, E.; Sallé, M.; Roncali, J. Chem. Mater. 2002, 14, 449-457. doi:10.1021/cm010756c

11. Mouffouk, F.; Higgins, S. J. Electrochem. Commun. 2006, 8, 15-20. doi:10.1016/j.elecom.2005.10.009

12. Bubnova, O.; Khan, Z. U.; Malti, A.; Braun, S.; Fahlman, M.; Berggren, M.; Crispin, X. Nat. Mater. 2011, 10, 429-433. doi:10.1038/nmat3012

13. Roncali, J.; Blanchard, P.; Frère, P. J. Mater. Chem. 2005, 15 , 1589-1610. doi:10.1039/B415481A

14. Camurlu, P. RSC Adv. 2014, 4, 55832-55845. doi:10.1039/C4RA11827H

15. Roncali, J. Chem. Rev. 1992, 92, 711-738. doi:10.1021/cr00012a009

16. Schottland, P.; Stéphan, O.; Le Gall, P.-Y.; Chevrot, C. J. Chim. Phys. Phys.-Chim. Biol. 1998, 95, 1258-1261. doi:10.1051/jcp:1998260

17. Hu, D.; Lu, B.; Duan, X.; Xu, J.; Zhang, L.; Zhang, K.; Zhang, S.; Zhen, S. RSC Adv. 2014, 4, 35597-35608. doi:10.1039/C4RA05075D

18. Balog, M.; Rayah, H.; Le Derf, F.; Sallé, M. New J. Chem. 2008, 32, 1183-1188. doi:10.1039/b715568a

19. Sassi, M.; Mascheroni, L.; Ruffo, R.; Salamone, M. M.; Pagani, G. A.; Mari, C. M.; D'Orazio, G.; La Feria, B.; Beverina, L. Org. Lett. 2013, 15, 3502-3505. doi:10.1021/ol401008s

20. Patai, S. The Carbon-Carbon Triple Bond; John Wiley \& Sons Ltd.: Bristol, 1978; Vol. 1 \& 2. doi:10.1002/9780470771563

21. Stang, P. J.; Diederich, F., Eds. Modern Acetylene Chemistry; VCH Verlagsgesellschaft mbH: Weinheim, 2007.

22. Chinchilla, R.; Nájera, C. Chem. Rev. 2014, 114, 1783-1826. doi:10.1021/cr400133p

23. Boyarskiy, V. P.; Ryabukhin, D. S.; Bokach, N. A.; Vasilyev, A. V. Chem. Rev. 2016, 116, 5894-5986. doi:10.1021/acs.chemrev.5b00514
24. Minkler, S. R. K.; Isley, N. A.; Lippincott, D. J.; Krause, N.; Lipshutz, B. H. Org. Lett. 2014, 16, 724-726. doi:10.1021/ol403402h 25. Ueda, H.; Yamaguchi, M.; Kameya, H.; Sugimoto, K.; Tokuyama, H. Org. Lett. 2014, 16, 4948-4951. doi:10.1021/ol5024695

26. Chinchilla, R.; Nájera, C. Chem. Rev. 2007, 107, 874-922. doi:10.1021/cr050992x

27. Kolb, H. C.; Finn, M. G.; Sharpless, K. B. Angew. Chem., Int. Ed. 2001, 40, 2004-2021. doi:10.1002/1521-3773(20010601)40:11<2004::AID-ANIE2004>3.0.CO ;2-5

28. Sinha, J.; Sahoo, R.; Kumar, A. Macromolecules 2009, 42, 2015-2022. doi:10.1021/ma802289j

29. Damaceanu, M.-D.; Mihaila, M.; Constantin, C.-P.; Chisca, S.; Serban, B.-C.; Diaconu, C.; Buiu, O.; Pavelescu, E. M.; Kusko, M. RSC Adv. 2015, 5, 53687-53699. doi:10.1039/C5RA07939J

30. Sienel, G.; Rieth, R.; Rowbottom, K. T. Epoxides. Ullmann's Encyclopedia of Industrial Chemistry; Wiley-VCH: Weinheim, 2000. doi:10.1002/14356007.a09_531

31. Tang, B.; Bray, C. D.; Pattenden, G. Tetrahedron Lett. 2006, 47, 6401-6404. doi:10.1016/j.tetlet.2006.06.150

32. Deis, R. C. Sorbitol and Mannitol. In Sweeteners and Sugar Alternatives in Food Technology, 2nd ed.; O'Donnell, K.; Kearsley, M. W., Eds.; Wiley-Blackwell: West Sussex, 2006; pp 249-261.

33. Sugisaki, C. H.; Ruland, Y.; Baltas, M. Eur. J. Org. Chem. 2003, 672-688. doi:10.1002/ejoc.200390108

34. Liang, Y.; Tao, Z.; Chen, J. Adv. Energy Mater. 2012, 2, 742-769. doi:10.1002/aenm.201100795

35. Ko, H. C.; Kang, M.; Moon, B.; Lee, H. Adv. Mater. 2004, 16, 1712-1716. doi:10.1002/adma.200400218

36. Sen, S.; Saraidaridis, J.; Kim, S. Y.; Palmore, G. T. R. ACS Appl. Mater. Interfaces 2013, 5, 7825-7830. doi:10.1021/am401590q

37. Monk, P. M. S. The Viologens: Physicochemical Properties, Synthesis and Applications of the Salts of 4,4'-Bipyridine; Wiley: New York, 1998.

38. Huang, X.; Yang, L.; Bergquist, J.; Strømme, M.; Gogoll, A.; Sjödin, M. J. Phys. Chem. C 2015, 119, 27247-27254.

doi:10.1021/acs.jpcc.5b08518

39. Iordache, A.; Oltean, M.; Milet, A.; Thomas, F.; Baptiste, B.; Saint-Aman, E.; Bucher, C. J. Am. Chem. Soc. 2012, 134, 2653-2671. doi:10.1021/ja209766e

40. Besbes, M.; Trippé, G.; Leviallain, E.; Mazari, M.; Le Derf, F.; Perepichka, I. F.; Derdour, A.; Gorgues, A.; Sallé, M.; Roncali, J. Adv. Mater. 2001, 13, 1249-1252.

doi:10.1002/1521-4095(200108)13:16<1249::AID-ADMA1249>3.0.CO; $2-\mathrm{W}$

41.Bu, H.-B.; Götz, G.; Reinold, E.; Vogt, A.; Schmid, S.; Blanco, R.; Segura, J. L.; Bäuerle, P. Chem. Commun. 2008, 1320-1322. doi:10.1039/b718077b 


\section{License and Terms}

This is an Open Access article under the terms of the Creative Commons Attribution License

(http://creativecommons.org/licenses/by/4.0), which permits unrestricted use, distribution, and reproduction in any medium, provided the original work is properly cited.

The license is subject to the Beilstein Journal of Organic Chemistry terms and conditions:

(http://www.beilstein-journals.org/bjoc)

The definitive version of this article is the electronic one which can be found at:

doi:10.3762/bjoc.12.265 